\title{
Common Fixed Point Theorem for Four Self-mappings with the Property $(C)$ in Cone Metric Spaces
}

\author{
K. Prudhvi \\ Department of Mathematics, University College of Science, Saifabad, Osmania University, Hyderabad, Telangana State, India
}

Copyright (C2016 by authors, all rights reserved. Authors agree that this article remains permanently open access under the terms of the Creative Commons Attribution License 4.0 International License.

\begin{abstract}
In this paper, we obtain a common fixed point theorem for four self-mappings with the property $(C)$ in cone metric spaces without assuming the regular cone. These results are extends, improves and generalization of some known results existing in the literature.
\end{abstract}

Keywords Cone Metric Space, Coincidence Point, Common Fixed Point, Weak Contraction, Property $(C)$

\section{Introduction and Preliminaries}

In 2007 , cone metric space was introduced by Huang and Zhang [5] which is a generalization of metric space by replacing the set of real numbers with an ordered Banach space and they obtained some fixed point theorems for contractive conditions in cone metric spaces by using the normal cone. After that, many authors are interest to extend this fixed point theorems in cone metric spaces with and without using normal cone (see, e.g. [2,3,4,6,9]). In 2002, the property (E, A) for self-mappings was introduced by Aamri and Moutawakil [1] obtained some fixed point theorems under strict contractive conditions. This property $(\mathrm{E}, \mathrm{A})$ is very useful in the study of fixed point theorems of non-expansive mappings (see, e.g, [8]). In 2012, the property (C) was introduced by S. Hyun Kim and B. Soo Lee [7], which is an extension of metric space property $(\mathrm{E}, \mathrm{A})$ into cone metric spaces and proved some fixed point theorems in cone metric spaces. In this paper, we proved a common fixed point theorem for four maps with property $(C)$ in cone metric spaces without assuming the regular cone which is an extension of the results of [7].

The following definitions are due to (2,5 and 7$)$.

Definition 1.1. [5] Let $E$ be a real Banach space and $P$ be a nonempty subset of $\mathrm{E}$. Then $\mathrm{P}$ is called a cone if and only if

(i). $\mathrm{P}$ is closed, non-empty and $\mathrm{P} \neq\{0\}$;

(ii). $a, b \in \mathbb{R}, a, b \geq 0, x, y \in P \Rightarrow a x+b y \in P$; (iii). $\mathrm{x} \in \mathrm{P}$ and $-\mathrm{x} \in \mathrm{P} \Rightarrow \mathrm{x}=0$.

Definition 1.2. [5] Let $P$ be a cone in a Banach space E, define partial ordering ' $\preccurlyeq$ ' with respect to $P$ by $x \preccurlyeq y$ if and only if $y-x \in P$. We shall write $x<y$ to indicate $x \leqslant y$ but $\mathrm{x} \neq \mathrm{y}$ while $\mathrm{x}<<\mathrm{y}$ will stand for $\mathrm{y}-\mathrm{x} \in$ intP, where int $\mathrm{P}$ denotes the interior of the set $\mathrm{P}$.

Definition 1.3. [5]Let $M$ be a nonempty set of $E$. Suppose that the map $\mathrm{d}: \mathrm{M} \times \mathrm{M} \rightarrow \mathrm{E}$ satisfies the following:

(i). $0 \preccurlyeq d(x, y)$ for all $x, y \in M$ and $\mathrm{d}(\mathrm{x}, \mathrm{y})=0$ if and only if $\mathrm{x}=\mathrm{y}$;

(ii). $d(x, y)=d(y, x) \quad$ for all $x, y \in M$;

(iii). $d(x, y) \preccurlyeq d(x, z)+d(y, z)$ for all $x, y, z \in M$.

Then $d$ is called a cone metric on $M$ and $(M, d)$ is called a cone metric space.

Definition 1.4. [5]Let $\left\{x_{n}\right\}$ be a sequence in $M$ and $x \in M$. If for every $\mathrm{c} \in$ int $\mathrm{P}$, where int $\mathrm{P} \neq \varnothing$ there is a natural number $\mathrm{N}$ such that for all $\mathrm{n}>\mathrm{N}, \mathrm{d}\left(\mathrm{x}_{\mathrm{n}}, \mathrm{x}\right)<<\mathrm{c}$, then we say that $\left\{\mathrm{x}_{\mathrm{n}}\right\}$ converges to $\mathrm{x}$ with respect to $\mathrm{P}$ and denotes as $\lim _{n \rightarrow \infty} x_{n}=\mathrm{x}$.

Lemma 1.5. [5] Let $P$ be a cone. Let $\left\{x_{n}\right\},\left\{y_{n}\right\}$ be sequences in $\mathrm{M}$. Then

(i) $\left\{x_{n}\right\}$ converges to $\mathrm{x}$ with respect to $\mathrm{P}$ if and only if $\mathrm{d}\left(\mathrm{x}_{\mathrm{n}}, \mathrm{x}\right) \rightarrow 0$ as $\mathrm{n} \rightarrow \infty$;

(ii) If $\mathrm{x}_{\mathrm{n}} \rightarrow \mathrm{x}$ and $\mathrm{y}_{\mathrm{n}} \rightarrow \mathrm{y}$ as $\mathrm{n} \rightarrow \infty$ with respect to $\mathrm{P}$, then $d\left(x_{n}, y_{n}\right) \rightarrow d(x, y)$ as $n \rightarrow \infty$

(iii) If $x_{n} \rightarrow x$ and $y_{n} \rightarrow y$ as $n \rightarrow \infty$ with respect to $P$, and $x_{n} \preccurlyeq y_{n}$ for all $n \in N$, then $x \preccurlyeq y$.

Definition 1.6. [2] For the mapping f, $g: X \rightarrow X$. If $w=$ $\mathrm{fz}=\mathrm{gz}$ for some $\mathrm{z}$ in $\mathrm{X}$, then $\mathrm{z}$ is called a coincidence point of $f$ and $g$ and $w$ is called a point of coincidence of $\mathrm{f}$ and $\mathrm{g}$.

Definition 1.7. [7] Two mappings $S, T: M \rightarrow M$ are weakly compatible if STx $=\mathrm{TSx}$, whenever $\mathrm{Sx}=\mathrm{Tx}$.

Definition 1.8. [7] Let $M$ be a non-empty set with a cone metric $d: M \times M \rightarrow(E, P)$. A mapping $T$ is said to satisfy the property $(C)$ if there is a sequence $\left\{x_{n}\right\}$ in $M$ such that 
$\lim _{n \rightarrow \infty} d\left(x_{n}, \mathrm{z}\right)=0=\lim _{n \rightarrow \infty} d\left(T x_{n}, \mathrm{z}\right)$ for some zEM.

Definition 1.9. [7] Let $X$ be a nonempty set with a cone metric $\mathrm{d}: \mathrm{M} \times \mathrm{M} \rightarrow(\mathrm{E}, \mathrm{P})$. A mapping $\mathrm{T}: \mathrm{M} \rightarrow \mathrm{M}$ is said to be generalized $(\psi, \varphi)$-weak contractive if for each $\mathrm{x}, \mathrm{y}$ $\in \mathrm{M}$,

$$
\psi(\mathrm{d}(\mathrm{Tx}, \mathrm{Ty})) \preccurlyeq \psi(\mathrm{d}(\mathrm{x}, \mathrm{y}))-\varphi(\mathrm{d}(\mathrm{x}, \mathrm{y})),
$$

where $\psi, \varphi \in \boldsymbol{\Phi}=\{\varphi: \mathrm{P} \rightarrow \mathrm{P}$ a continuous mapping satisfying $\varphi(\mathrm{t})=0$ if and only if $\mathrm{t}=0\}$.

\section{Main Results}

In this section, we prove a common fixed theorem for four maps with property (C) in cone metric spaces without assuming the regular cone.

The following theorem is an extension and improves the Theorem 3.1 of [7].

Theorem 2.1. Let $\mathrm{M}$ be a nonempty set with cone metric $\mathrm{d}$ : $\mathrm{M} \times \mathrm{M} \rightarrow(\mathrm{E}, \mathrm{P})$ and $\mathrm{S}, \mathrm{T}, \mathrm{I}, \mathrm{J}: \mathrm{M} \rightarrow \mathrm{M}$ be self-mappings satisfying the property $(\mathrm{C}), \mathrm{I}$ and $\mathrm{J}$ are onto, and for each $\mathrm{X}$, $\mathrm{y} \in \mathrm{M}$,

$(\mathrm{d}(\mathrm{Tx}, \mathrm{Sy})) \preccurlyeq(\mathrm{d}(\mathrm{Ix}, \mathrm{Iy}))-\boldsymbol{\varphi}(\mathrm{d}(\mathrm{Jx}, \mathrm{Jy})), \quad$ for $\boldsymbol{\psi}, \boldsymbol{\phi} \in \boldsymbol{\phi}$.

Then $\mathrm{S}, \mathrm{T}, \mathrm{I}$ and $\mathrm{J}$ have a coincidence point in $\mathrm{M}$. Moreover, $\{\mathrm{S}, \mathrm{J}\}$ and $\{\mathrm{T}, \mathrm{I}\}$ are weakly compatible, then $\mathrm{S}$, $\mathrm{T}$, I and $\mathrm{J}$ have a unique common fixed point.

Proof: Let $\left\{\mathrm{x}_{\mathrm{n}}\right\}$ be a sequence in M satisfying

$$
\begin{gathered}
\lim _{n \rightarrow \infty} d\left(I x_{n}, \mathrm{z}\right)=\lim _{n \rightarrow \infty} d\left(S x_{n}, \mathrm{Ia}\right) \\
=\lim _{n \rightarrow \infty} d\left(J x_{n}, \mathrm{ja}\right)=\lim _{n \rightarrow \infty} d\left(T x_{n}, \mathrm{Ja}\right)=0,
\end{gathered}
$$

for some $\mathrm{z} \in \mathrm{M}$.

Take $\mathrm{a} \in \mathrm{M}$ such that $\mathrm{z}=\mathrm{Ia}=\mathrm{Ja}$, then

$$
\begin{gathered}
\lim _{n \rightarrow \infty} d\left(I x_{n}, \mathrm{Ia}\right)=\lim _{n \rightarrow \infty} d\left(J x_{n}, \mathrm{z}\right) \\
=\lim _{n \rightarrow \infty} d\left(T x_{n}, \mathrm{z}\right)=\lim _{n \rightarrow \infty} d\left(S x_{n}, \mathrm{z}\right)=0 .
\end{gathered}
$$

Since, $\boldsymbol{\psi}\left(\mathrm{d}\left(\mathrm{Sa}, \mathrm{Tx}_{\mathrm{n}}\right)\right) \preccurlyeq \boldsymbol{\psi}\left(\mathrm{d}\left(\mathrm{Ia}, \mathrm{x}_{\mathrm{n}}\right)\right)-\varphi\left(\mathrm{d}\left(\mathrm{Ja}, \mathrm{Jx}_{\mathrm{n}}\right)\right)$.

We have,

$$
\begin{aligned}
& \lim _{n \rightarrow \infty} \psi\left(\mathrm{d}\left(\mathrm{Sa}, \mathrm{Tx} \mathrm{x}_{\mathrm{n}}\right)\right) \preccurlyeq \lim _{n \rightarrow \infty}\left\{\psi\left(\mathrm{d}\left(\mathrm{Ia}, \mathrm{Ix}_{\mathrm{n}}\right)\right)-\varphi\left(\mathrm{d}\left(\mathrm{Ja}, \mathrm{Jx}_{\mathrm{n}}\right)\right)\right\} . \\
& \Rightarrow \psi(\mathrm{d}(\mathrm{Sa}, \mathrm{Ja}) \preccurlyeq \boldsymbol{\psi}(\mathrm{d}(\mathrm{Ia}, \mathrm{Ia}))-\boldsymbol{\varphi}(\mathrm{d}(\mathrm{Ja}, \mathrm{Ja})) . \\
& \Rightarrow \psi(\mathrm{d}(\mathrm{Sa}, \mathrm{Ja})=0 . \\
& \Rightarrow \mathrm{Sa}=\mathrm{Ja} .
\end{aligned}
$$

And, $\psi\left(\mathrm{d}\left(\mathrm{Sx}_{\mathrm{n}}, \mathrm{Ta}\right)\right) \preccurlyeq \boldsymbol{\psi}\left(\mathrm{d}\left(\mathrm{Ix}_{\mathrm{n}}, \mathrm{Ia}\right)\right)-\boldsymbol{\varphi}\left(\mathrm{d}\left(\mathrm{Jx}_{\mathrm{n}}, \mathrm{Ja}\right)\right)$.

We have,

$\lim _{n \rightarrow \infty} \psi\left(\mathrm{d}\left(\mathrm{Sx}_{\mathrm{n}}, \mathrm{Ta}\right)\right) \preccurlyeq \lim _{n \rightarrow \infty}\left\{\psi\left(\mathrm{d}\left(\mathrm{Ix}_{\mathrm{n}}, \mathrm{Ia}\right)\right)-\varphi\left(\mathrm{d}\left(\mathrm{Jx}_{\mathrm{n}}, \mathrm{Ja}\right)\right)\right\}$.

$\Rightarrow \boldsymbol{\psi}(\mathrm{d}(\mathrm{Ia}, \mathrm{Ta})) \preccurlyeq \boldsymbol{\psi}(\mathrm{d}(\mathrm{Ia}, \mathrm{Ia}))-\varphi(\mathrm{d}(\mathrm{Ja}, \mathrm{Ja}))$.

$\Longrightarrow \psi \mathrm{d}(\mathrm{Ia}, \mathrm{Ta})=0$.

$\Rightarrow \mathrm{Ta}=\mathrm{Ia}$.

From (3) and (4) it follows that

$$
\mathrm{Sa}=\mathrm{Ja}=\mathrm{Ta}=\mathrm{Ia}(=\mathrm{z}) .
$$

Since, $\{\mathrm{S}, \mathrm{J}\}$ and $\{\mathrm{T}, \mathrm{I}\}$ are weakly compatible.

$\psi(\mathrm{d}(\mathrm{Sa}, \mathrm{SSa}))=\boldsymbol{\psi}(\mathrm{d}(\mathrm{Sa}, \mathrm{TSa}))$

$\preccurlyeq \boldsymbol{\psi}(\mathrm{d}(\mathrm{Ia}, \mathrm{ISa}))-\varphi(d(\mathrm{Ja}, \mathrm{JSa}))$

$=(\mathrm{d}(\mathrm{Sa}, \mathrm{SSa}))-\varphi(d(\mathrm{Sa}, \mathrm{SSa}))$

$\Longrightarrow \varphi(\mathrm{d}(\mathrm{Sa}, \mathrm{SSa})) 0$.

$\Longrightarrow \mathrm{d}(\mathrm{Sa}, \mathrm{SSa})=0$.

That is,

$\mathrm{z}=\mathrm{Sa}=\mathrm{SSa}$,

$\mathrm{Sa}(=\mathrm{z})$ is a fixed point of $\mathrm{S}$.

And

$\boldsymbol{\psi}(\mathrm{d}(\mathrm{Ja}, \mathrm{JJa}))=\boldsymbol{\psi}(\mathrm{d}(\mathrm{Sa}, \mathrm{TJa}))$

$\preccurlyeq \psi(\mathrm{d}(\mathrm{Ia}, \mathrm{IJa}))-\varphi(d(\mathrm{Ja}, \mathrm{JJa}))$

$=\psi(\mathrm{d}(\mathrm{Ja}, \mathrm{JJa}))-\varphi((\mathrm{Ja}, \mathrm{JJa}))$

$\Longrightarrow \varphi(\mathrm{d}(\mathrm{Ja}, \mathrm{JJa})) \preccurlyeq 0$.

$\Rightarrow \mathrm{d}(\mathrm{Ja}, \mathrm{JJa})=0$.

That is, $\mathrm{z}=\mathrm{Ja}=\mathrm{JJa}$,

$\mathrm{Ja}(=\mathrm{z})$ is a fixed point of $\mathrm{J}$.

Since, $\mathrm{z}(=\mathrm{Sa}=\mathrm{Ja})$.

Therefore,

$\mathrm{Z}$ is a common fixed point of $\mathrm{S}$ and $\mathrm{J}$.

Similarly, we get that

$\mathrm{z}=\mathrm{Ta}=\mathrm{T}$ Ta and $\mathrm{z}=\mathrm{Ia}=\mathrm{I}$ Ia.

Since, $\mathrm{z}(=\mathrm{Ta}=\mathrm{Ia})$.

Therefore,

$\mathrm{Z}$ is a common fixed point of $\mathrm{T}$ and $\mathrm{I}$.

$\mathrm{z}=\mathrm{Ta}=\mathrm{Sa}=\mathrm{Ta}=\mathrm{Ia}=\mathrm{Ja}$.

Therefore, S, T, I, and J have a common fixed point. Uniqueness, let $\mathrm{S}, \mathrm{T}, \mathrm{I}$ and $\mathrm{J}$, have two distinct fixed points $\mathrm{w}=\mathrm{Sw}=\mathrm{Tw}=\mathrm{Iw}=\mathrm{Jw}$ and $\mathrm{z}=\mathrm{Sz}=\mathrm{Tz}=\mathrm{Iz}=\mathrm{Jz}$ in $\mathrm{M}$, then $\psi(\mathrm{d}(\mathrm{Tz}, \mathrm{Sw})) \preccurlyeq \psi(\mathrm{d}(\mathrm{Iz}, \mathrm{Iw}))-\boldsymbol{\varphi}(\mathrm{d}(\mathrm{Jz}, \mathrm{Jw}))$

$=\psi(\mathrm{d}(\mathrm{Tz}, \mathrm{Sw}))-\boldsymbol{\varphi}(\mathrm{d}(\mathrm{Tz}, \mathrm{Sw}))$

$\Rightarrow \boldsymbol{\varphi}(\mathrm{d}(\mathrm{Tz}, \mathrm{Sw}))=0$.

$\Rightarrow \mathrm{d}(\mathrm{Tz}, \mathrm{Sw})=0$. That is, $\mathrm{Tz}=\mathrm{Sw}$.

$\Rightarrow \mathrm{z}=\mathrm{w}$.

Therefore, S, T, I and J have a unique common fixed point.

Remark 2.2. By putting $(\mathrm{t})=\mathrm{t}$ and $(\mathrm{t})=0$ in the above Theorem 2.1, then we obtain the following theorem.

Theorem 2.3. Let $\mathrm{M}$ be a nonempty set with cone metric $\mathrm{d}: \mathrm{M} \times \mathrm{M} \rightarrow(\mathrm{E}, \mathrm{P})$ and

$\mathrm{S}, \mathrm{T}, \mathrm{I}: \mathrm{M} \rightarrow \mathrm{M}$ be self-mappings satisfying the property (C), I is onto, and for each $\mathrm{x}, \mathrm{y} \in \mathrm{M}$,

$$
\mathrm{d}(\mathrm{Tx}, \mathrm{Sy}) \preccurlyeq \mathrm{d}(\mathrm{Ix}, \mathrm{Iy}) .
$$

Then S, T and I have a coincidence point in M. Moreover, if $\{\mathrm{S}, \mathrm{I}\}$ and $\{\mathrm{T}, \mathrm{I}\}$ are weakly compatible, then $\mathrm{S}, \mathrm{T}$ and $\mathrm{I}$ 
have a unique common fixed point.

Remark 2.4. If we choose $\mathrm{S}=\mathrm{T}$, and $\mathrm{I}=\mathrm{S}$ and $\mathrm{J}=\mathrm{S}$ in the above Theorem 2.1, then we obtain the Theorem 3.1 of [7].

Remark 2.5. If we choose $\mathrm{S}=\mathrm{T}$, and $\mathrm{I}=\mathrm{S}$ and $\mathrm{J}=\mathrm{S}$ and putting $\psi(\mathrm{t})=\mathrm{t}$ and $\varphi(\mathrm{t})=0$ in the above Theorem 2.1, then we obtain the following theorem.

Theorem 2.6.(Theorem 3.2[7]) Let $M$ be a nonempty set with cone metric $\mathrm{d}: \mathrm{M} \times \mathrm{M} \rightarrow(\mathrm{E}, \mathrm{P})$ and $\mathrm{S}, \mathrm{T}: \mathrm{M} \rightarrow \mathrm{M}$ be mappings satisfying the property $(\mathrm{C}), \mathrm{S}$ is onto, and for each $\mathrm{x}, \mathrm{y} \in \mathrm{M}$

$$
\mathrm{d}(\mathrm{Tx}, \mathrm{Ty}) \preccurlyeq \mathrm{d}(\mathrm{Sx}, \mathrm{Sy}) .
$$

Then $\mathrm{S}$ and $\mathrm{T}$ have a coincidence point in M. Moreover, if $\{\mathrm{S}, \mathrm{T}\}$ is weakly compatible, then $\mathrm{S}$ and $\mathrm{T}$ have a unique common fixed point.

The following theorem in Abbas and Jungck [2] is a corollary of the above Theorem 2.6.

Theorem 2.7.Let (X, d) be a cone metric space, and $\mathrm{P}$ be a normal cone with the normal constant $\mathrm{L}$. Suppose that $\mathrm{S}, \mathrm{T}$ : $\mathrm{M} \rightarrow \mathrm{M}$ satisfy

$$
\mathrm{d}(\mathrm{Tx}, \mathrm{Ty}) \preccurlyeq \mathrm{kd}(\mathrm{Sx}, \text { Sy), for all } \mathrm{x}, \mathrm{y} \in \mathrm{M},
$$

where, $k \in[0,1)$ is a constant. If the range of $S$ contains the range of $\mathrm{T}$ and $\mathrm{S}(\mathrm{M})$ is a complete subspace of $\mathrm{M}$, then $\mathrm{S}$ and $\mathrm{T}$ have a coincidence point in $\mathrm{M}$. Moreover, if $\{\mathrm{S}, \mathrm{T}\}$ is weakly compatible, then $\mathrm{S}$ and $\mathrm{T}$ have a unique common fixed point.

\section{Acknowledgements}

I am very grateful to experts for their appropriate and constructive suggestions to improve this paper.

\section{REFERENCES}

[1] M. Aamri and D. E. Moutawakil, Some new common fixed point theorems under stric contractive conditions, J. Math. Anal. Appl. 270(2002), 181-188.

[2] M. Abbas and G. Jungck, Common fixed point results for noncommuting mappings without continuity in cone metric spaces, J. Math. Anal. Appl. 341(2008), 416-420.

[3] I. Altun, G. Durmaz, Some fixed point theorems on ordered cone metric spaces, Rend. Ciric. Mat. Palermo 58(2009) 319-325.

[4] P. N. Dutta and B. S. Choudary, A generalization of contraction principle in metric spaces, Fixed Point Theory Appl. (2008), Article ID 406386, 8 pages.

[5] L. G. Huang, X. Zhang, Cone metric spaces and fixed point theorems of contractive mappings, J. Math. Anal. Appl. 332 (2) (2007)1468-1476.

[6] D. IIic, V. Rakocevic, Common fixed points for maps on cone metric space, J. Math. Anal. Appl. 341(2008)876-882.

[7] S. H. Kim and B. S. Lee, Generalized fixed point theorems in cone metric spaces, Korean J. Math. 20 (2012), No.3, pp, 353-360.

[8] R. P. Pant, Fixed points of nonexpansive mappings and a generalized notion of compactness, Bull. Calcutta Math. Soc. 99 (1) (2007), 45-52. 